\title{
What rheumatologists need to know about innate lymphocytes
}

DOI:

10.1038/nrrheum.2016.140

\section{Document Version}

Accepted author manuscript

Link to publication record in Manchester Research Explorer

\section{Citation for published version (APA):}

Exley, M. A., Tsokos, G. C., Mills, K., Elewaut, D., \& Mulhearn, B. (2016). What rheumatologists need to know about innate lymphocytes. Nature Reviews Rheumatology. https://doi.org/10.1038/nrrheum.2016.140

\section{Published in:}

Nature Reviews Rheumatology

\section{Citing this paper}

Please note that where the full-text provided on Manchester Research Explorer is the Author Accepted Manuscript or Proof version this may differ from the final Published version. If citing, it is advised that you check and use the publisher's definitive version.

\section{General rights}

Copyright and moral rights for the publications made accessible in the Research Explorer are retained by the authors and/or other copyright owners and it is a condition of accessing publications that users recognise and abide by the legal requirements associated with these rights.

\section{Takedown policy}

If you believe that this document breaches copyright please refer to the University of Manchester's Takedown Procedures [http://man.ac.uk/04Y6Bo] or contact uml.scholarlycommunications@manchester.ac.uk providing relevant details, so we can investigate your claim.

\section{OPEN ACCESS}




\title{
What the rheumatologist needs to know about innate lymphocytes
}

\author{
Mark A. Exley, ${ }^{1,2,3}$ George C. Tsokos, ${ }^{4}$ Kingston H.G. Mills, ${ }^{5}$ Dirk Elewaut ${ }^{6,7}$ \\ \& Ben Mulhearn ${ }^{1}$ \\ ${ }^{1}$ Manchester Collaborative Centre for Inflammation Research (MCCIR), \\ University of Manchester, Manchester, UK \\ ${ }^{2}$ Gastroenterology, Hepatology \& Endoscopy, Brigham \& Women's Hospital, Harvard Medical \\ School, Boston, MA, USA \\ ${ }^{3}$ Agenus, Inc., Lexington, MA, USA \\ ${ }^{4}$ Rheumatology, Beth Israel Deaconess Medical Center, \\ Harvard Medical School, Boston, MA, USA \\ ${ }^{5}$ School of Biochemistry and Immunology, Trinity Biomedical Science Institute, Trinity \\ College, Dublin, Ireland \\ ${ }^{6}$ Laboratory for Molecular Immunology and Inflammation, Department of Rheumatology, \\ Ghent University Hospital, Ghent, Belgium \\ ${ }^{7}$ VIB Inflammation Research Center, Ghent University, Ghent, Belgium
}

Corresponding address:

Mark A. Exley

Brigham \& Women's Hospital, 75 Francis St., Thorn 1405, Boston, MA 02115, USA

mexley@partners.org

mark.exley@manchester.ac.uk 


\section{Abstract}

As innate immune fast responders, innate lymphocytes (ILs) can have protective or pathogenic roles in the initiation as well as maintenance of immunity in general, and also contribute to tissue homeostasis among other functions. ILs also appear to be involved in autoimmunity in particular. Recently it has become clear that different populations of ILs can have roles in responding to antigen-specific autoantibody and autoreactive $T$ cells and thereby amplifying or regulating disease. In autoimmune processes, IL involvement can manifest as protective regulatory or pro-inflammatory cytokine responses. Cytotoxicity is also a cardinal feature of many ILs and can contribute to inflammatory tissue damage. Finally, ILs can respond to biologic therapies for autoimmune diseases. Therefore, like TNF and other effector molecules, appropriate IL subsets may be appropriate targets to ameliorate various autoimmune diseases. (131 words)

Key points:

Innate lymphocytes (ILs) can have protective or pathogenic roles in the initiation and maintenance of immunity and other functions.

Different IL types also appear to be involved positively or negatively in autoimmunity.

IL involvement can be via protective regulatory or pro-inflammatory cytokine production and cytotoxic tissue damage.

ILs can also respond to biologic therapies for autoimmune diseases.

Therefore, IL subsets may be appropriate targets in various autoimmune diseases

Keywords / Abbreviations:

Natural Killer (NK) cells; Natural Killer T (NKT) cells; invariant NKT (iNKT) cells; Innate Lymphoid cells (ILC), Mucosal Associated invariant T (MAiT) cells; gammadelta $(\gamma \delta) T$ cells, Innate-like B (ILB) cells. 


\section{Introduction}

The immune system recognizes pathogenic microbial attack to maintain life in the literal (and later metaphorical) sea of potential infectious agents that multicellular life evolved in. However, the situation is much more complex, with microorganisms masquerading as 'self', commensal organisms even benefiting the host one day, year, or decade, and the next becoming opportunistic pathogens. Furthermore, the 'self' can become the 'other', foreign, and stimulate immune components which would normally be protective. While in many individuals this will not lead to clinical symptoms, in those predisposed and exposed to particular microbial waves, this does eventually lead to one or more of the spectrum of autoimmune diseases (Figure 1). Restoring the balance of the healthy immune system is one approach to treat autoimmune disease. Recent advances promise to contribute to further restoration of health in autoimmune diseases, which have been already subject to a quantum leap forward with the advent of biologic therapies. Therefore, when developing effective anti-inflammatory interventions, the challenge remains to identify the components and pathways that are primarily pathogenic (Figure 1) and to develop strategies that mitigate the pathogenic effects without significantly compromising the protective functions of the system as a whole or inducing further complications, such as increased susceptibility to infection or cancer (Figure 2). Understanding the targets in autoimmune diseases promises better therapeutic control of these autoimmune diseases.

Immune cells represent numerous subsets but two broad functional differences are immediately obvious:

1. Myeloid and lymphoid immune cells.

2. Innate and adaptive immune cells.

ILs have been variously described as including innate lymphoid cells, innate-like lymphocytes, and unconventional T cells, to name a few ${ }^{1}$. This is confusing, and it may first seem that the terms 'innate' and 'lymphocyte' are mutually exclusive. While not all innate cells are myeloid, as we shall see below, all adaptive immune cells are lymphocytes (classic B and T cells). This review will be restricted to innate lymphocyte subsets cells (Table 1), other than a brief definition of myeloid cells and comparisons with classic B and T cells; see Section B). It will summarize involvement of innate lymphocyte types in autoimmune diseases and response to treatment (Sections C, D). 
The following cell types are widely considered ILs and will be discussed in turn:

Natural Killer (NK) cells; Natural Killer T (NKT) cells; invariant NKT (iNKT) cells; Innate Lymphoid cells (ILC), Mucosal Associated invariant T (MAiT) cells; gamma-delta $(\gamma \delta)$ T cells, Innate-like B (ILB) cells.

Those who wish to understand these more recently-described cell types can proceed from the beginning onwards in sequence. The more harried Rheumatologist (!) might prefer to jump to Section $\mathbf{C}$ and, based on interest generated, move back to find out more about the relevant different IL populations in Section B or on to the final Sections. We also describe in the latter the impact of biologic therapies on the various IL populations (Section D), strengths and limitations of animal models (Box 1) and targeting prospects of different ILs (Box 2) and finally summarize key findings and future prospects (Section E). 


\section{A. Overview - contributors to autoimmune inflammation}

Acute inflammation is a critical mechanism for protecting the host against infection and tissue injury (Figure 2). Such inflammation, whether infectious or sterile in origin, is characterized by immune cell infiltration into target tissues to orchestrate the killing and removal of either infected or damaged cells (Figure 1), and subsequently to promote tissue repair and regeneration. Chronic inflammation occurs when an acute response fails to resolve due to the continued presence of an inducer of inflammation, or a lack of normal immuno-regulation. The excessive and persistent presence of cytotoxic immune cells and their mediators play important roles in the pathogenesis of numerous human diseases, including autoimmune diseases.

Several pro-inflammatory mediators that contribute to the development of autoimmune disease (against a background of failed immuno-regulation) are produced by a spectrum of innate immune cell types (Table 1). The relative contributions of these innate lymphocytes to autoimmunity and inflammation will be discussed below.

Tumor necrosis factor- $\alpha$ (TNF- $\alpha$ ) is such a prototypical example and was one of the first pro-inflammatory cytokines linked with autoimmune diseases. Its success as a target in biological therapies has dramatically altered treatment algorithms in rheumatology. More recently, the interleukin-17 (IL-17), IL-23, transforming growth factor- $\beta$ (TGF- $\beta$ ) and IL-1 $\beta$ axis has been implicated in autoimmune inflammation ${ }^{2}$. This maybe further amplified by IL-33 or its soluble receptor (sST2, suppression of tumorigenicity 2) in some diseases. For example, serum IL-33 and SST2 levels are elevated in primary Sjogren syndrome patients versus subjects with SLE as well as healthy controls ${ }^{3}$. In vitro, IL-33 did not alone increase pro-inflammatory cytokine secretion, but acted synergistically with IL-12 and IL23 to promote IFN-Y production ${ }^{3}$. However, disappointing results from clinical trials to inhibit some of these components have suggested redundancy in these cytokine pathways. Sources of and targets for some of these cytokines include ILs (Table 1), as discussed below, which represent alternative targets to the effector molecules in autoimmunity. 


\section{B. Innate lymphocytes}

Let us first consider that a cell of the adaptive immune system is one which is able to successfully rearrange its antigen receptor (i.e. B cell receptor, or antibody; and a T cell receptor) to create a vast number of specificities capable of recognising a universe of potential pathogen epitopes. Naïve B and T cells need priming by antigen on antigenpresenting cells to mature to fully competent antibody-secreting B cells or effector $\mathrm{T}$ cells. In contrast, a cell of the innate immune system has its controlling receptor(s) 'set in stone': encoded in germline DNA and therefore does not create such diversity but evolved to rapidly respond to common pathogen-associated molecular patterns typically with mass cytokine production and cytolysis of infected cells to limit immediate infectious spread before the adaptive immune system can mobilize to clear the infection. This leads us to ILs which are found in a mature state 'ready for action' and can be classified into two broad groups:

- Cells derived from the lymphoid lineage but that do not undergo any receptor rearrangement. NK cells, for instance, and others which have now been characterized, are generally known as innate lymphoid cells, which have subsequently been grouped according to the type of cytokines they produce, mirroring the $T$ helper cell subsets.

- Cells which have similar characteristics to T cells and which rearrange their T cell receptors, but which are selected on mono-morphic restriction molecules, so do so in a way which tends to produce an abundance of T cell specificities. They also may not use the $\alpha$-and $\beta$ - chain of the T cell receptor (in the case of $\gamma \delta$ T cells), mostly recognize non-peptidic antigens and not in conjunction with classical MHC molecules (i.e. MAIT cells, NKT cells). These have been known as unconventional T cells and innate-like lymphocytes. They also gain the title of 'innate' because they are able to produce large amounts of cytokines rapidly, on recognition of certain fixed molecular patterns, much like other innate cells.

In this section it should finally be pointed out that, on the whole, ILs share a common ability to enter tissues, rather than lymphoid organs like the majority of classical $B$ and $T$ cells. It is therefore only ILs and a subset of effector memory and regulatory $T$ cells which are directly positioned accordingly to positively or negatively influence tissue-specific autoimmune diseases. 


\begin{tabular}{|c|c|c|c|c|}
\hline Innate Subset & Phenotype & Key Products & Roles & Refs. \\
\hline \multicolumn{5}{|l|}{ Group 1 ILCs } \\
\hline ILC1 & 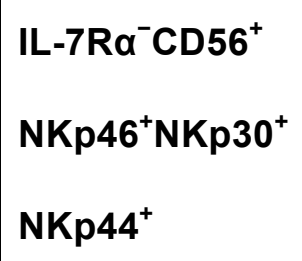 & $\begin{array}{l}\text { IFN } \gamma \text {, Mac activates } \\
\text { Variable Grn, Pfp } \\
\text { Variably cytotoxic }\end{array}$ & $\begin{array}{l}\text { Pro- } \\
\text { inflammatory }\end{array}$ & 1,4 \\
\hline NK cell & $\begin{array}{l}\text { NK locus, KIR }{ }^{+} \\
\text {CD56 }^{\text {high }} \text { CD16 } \\
\text { CD56 }^{\text {low }} \text { CD } 16^{+}\end{array}$ & $\begin{array}{l}\text { IFN } \gamma, \quad \text { Grn, } \\
\text { PfpCytotoxicity }\end{array}$ & $\begin{array}{l}\text { Viral } \\
\text { immunity } \\
\text { Tumour } \\
\text { surveillance }\end{array}$ & 5,6 \\
\hline \multicolumn{5}{|l|}{ Group 2 ILCs } \\
\hline ILC2 & $\begin{array}{l}\text { IL-7R } \alpha^{+} \text {CD45 } \\
\text { ST2, KLRG1 } \\
\text { CD161 }^{+} \text {CRTH2 }^{+}\end{array}$ & $\begin{array}{l}\text { IL-4, IL-5, IL-9, IL- } \\
\text { 13, GM-CSF }\end{array}$ & $\begin{array}{l}\text { Pro-fibrotic, } \\
\text { Healing, } \\
\text { Helminth } \\
\text { immunity }\end{array}$ & 4,7 \\
\hline \multicolumn{5}{|l|}{ Group 3 ILCs } \\
\hline ILC3 & 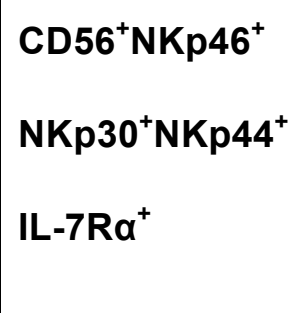 & $\begin{array}{l}\text { IL-17, IL-22, } \\
\text { variable TNF } \alpha, \\
\text { GM-CSF, LT }\end{array}$ & $\begin{array}{l}\text { Bacterial ctrl } \\
\text { Pro- } \\
\text { inflammatory, } \\
\text { Homeostatic }\end{array}$ & $1,4,8,9$ \\
\hline \multicolumn{5}{|c|}{ Innate-like lymphocytes / Unconventional T cells (TCR+ BCR+ ILs) } \\
\hline iNKT cells & $\begin{array}{l}\text { V } \alpha 24 \mathrm{~J} \alpha 18 \\
\text { NKRs incl. }\end{array}$ & $\begin{array}{l}\text { Th1 / Th2 } \\
\text { / Th17 / Treg }\end{array}$ & $\begin{array}{l}\text { Context- } \\
\text { dependent } \\
\text { immune }\end{array}$ & $10-17$ \\
\hline
\end{tabular}




\begin{tabular}{|c|c|c|c|c|}
\hline & CD161, NKG2D & Cytotoxic & enhancement & \\
\hline yঠ T cells & YठTCRs; NKRs & IFN $\gamma$, TNF $\alpha$, etc. & $\begin{array}{l}\text { Multi-subsets } \\
\text { Anti-pathogen }\end{array}$ & $18-22$ \\
\hline MAIT Cells & $\begin{array}{l}\mathrm{V}_{\alpha 7.2 \mathrm{~J} \alpha 33} \\
\mathrm{CD} 161\end{array}$ & $\begin{array}{l}\text { IFN } \gamma, \text { TNF } \alpha \text {, etc. } \\
\text { Cytotoxic }\end{array}$ & Bacterial ctrl & $23-26$ \\
\hline \multicolumn{5}{|c|}{ Innate-like B cells } \\
\hline $\begin{array}{l}\text { B-1 cells } \\
\text { MZ B cells } \\
\text { B10 cells }\end{array}$ & $\begin{array}{l}\mathrm{CD}^{+} / \mathrm{CD}^{-} \\
\mathrm{CD}^{-} 7^{+} \\
\mathrm{CD}^{+}{ }^{+} \\
\mathrm{CD}^{-}\end{array}$ & $\begin{array}{l}\text { GM-CSF } \\
\text { IL-10 }\end{array}$ & $\begin{array}{l}\text { Bacterial ctrl } \\
\text { Natural lg } \\
\text { Regulatory }\end{array}$ & $27-30$ \\
\hline
\end{tabular}

Table 1: Innate Lymphocyte Lineages: IL subsets and summary distinguishing phenotypes, products and functions. NK locus: C-type lectin superfamily members encoded in same locus in mammals and including CD94, CD161, NKG2 subfamily, expressed on many ILs. NKRs: NK cell receptors, including NK locus molecules, common to NK, NKT and other IL subsets. Note, NK locus and NKR are not expressed by naïve B or T cells, but are expressed by some effector / memory mature $\mathrm{T}$ cells, particularly cytotoxic CD8 and tissue-tropic helper CD4 memory adaptive $\mathrm{T}$ cell subsets. Consequently, for example, $\sim 25 \%$ of adult human T cells express CD161. Bacterial control: Commensal mucosal as well as invasive pathogens. TCR: T cell receptor. Mac: Macrophage. Grn: Granzymes. Pfp: Perforin. LT: Lymphotoxin. 'B-1' B cells: natural B cells as distinct from adaptive / classical 'B-2' B cells. B10 B cells: regulatory IL-10 producing B cells. MZ: Marginal zone. Ig: Immunoglobulin. 


\section{Natural killer (NK) cells}

NK cells are involved in immunosurveillance and are now usually classified as a subset of innate lymphoid cells. CD56 ${ }^{\mathrm{dim}} \mathrm{CD} 16^{+} \mathrm{NK}$ cells are directly cytotoxic whereas CD56 ${ }^{\text {bright }}$ CD16 ${ }^{-}$NK cells are able to produce pro-inflammatory (Th1) cytokines, such as interferon- $\gamma$ (IFN- $\gamma$ ), and TNF- $\alpha$. They have a clear role in controlling virally-infected and neoplastic cells by direct cytotoxicity or by producing IFN-y and other Th1 cytokines which increase the killing potential of other cells such as $T$ cells and macrophages.

NK cells express different combinations of inhibitory and activating receptors and are therefore able to respond to a variety of signals in different conditions. Inhibitory receptors include NK cell receptors which recognize MHC class I molecules, and can become activated if they encounter a lack of MHC class I molecules on target cells, known as the 'missing-self' hypothesis ${ }^{31}$. The 'missing-self' hypothesis proved that cells which lose the ability to display self-antigens via MHC class I molecules on their surface, such as cancer cells and virally infected cells, can be identified as foreign by NK cells and destroyed by direct cell-mediated cytotoxicity. The association of autoimmunity with prior infection could partly involve class 1 down-regulation, which could unleash NK activity (see below).

\section{Innate lymphoid cells (ILCs)}

ILCs (reviewed in ${ }^{32}$ ) are a newly-recognized family of leucocytes which may hold vital roles in bridging innate and adaptive immunity. Importantly and similarly to NK cells, they do not express rearranged antigen receptors in the same way that conventional $B$ and $T$ cells do. Indeed, NK cells are now generally grouped with similar cells into group 1 ILCs, which both produce prototypical Th1 cytokines. Furthermore, other ILC subtypes express NK markers, making discrimination and targeting of each ILC subset complicated.

When organs are injured during the onset of autoimmune diseases, antigen-presenting cells (APCs) elicit immune responses by producing factors such as TNF- $\alpha$, transforming growth factor- $\beta$ (TGF- $\beta$ ), and reactive oxygen species (ROS), which can stimulate ILCs as well as other lymphocytes ILCs which are classified into group 1, group 2 and group 3 ILCs depending on the cytokine profile of the $\mathrm{T}$ helper cell subset they mirror. For instance: group 1 ILC cells such as conventional NK cells and ILC1 cells produce type 1 
cytokines, namely IFN-ץ; group 2 ILCs produce the type 2 cytokines IL-5, IL-9 and IL-13; and group 3 ILCs are able to produce IL-17, IL-22 and other Th17 cytokines. Furthermore, ILCs are able to produce cytokines rapidly upon activation ${ }^{1}$.

\section{Natural killer T (NKT) cells}

NKT cells carry the hallmarks of both NK cells and T cells and are functionally defined as being CD1d-restricted, in that their T cell receptor (TCR) will recognize antigen presented by $\mathrm{CD} 1 \mathrm{~d}$ molecules on $\mathrm{APCs}^{33}$. In general, NKT cells are able to rapidly produce high levels of various cytokines and chemokines and have CD1d-specific cytotoxicity. In humans and mice, NKT cells have physiological roles in anti-tumor and anti-viral responses $^{34,35}$.

NKT cells are postulated to have diverse biological functions ${ }^{36}$ with the ability to produce large amounts of both Th1 and Th2 cytokines on stimulation with different endogenous and exogenous ligands ${ }^{37}$. The term 'NKT' encompasses a variety of cells with different phenotypes $^{38}$. The best-described NKT cells are invariant NKTs, or iNKTs. There are also 'non-invariant' ('diverse' or 'Type 2') CD1d-reactive NKT populations in blood and tissues. In humans, iNKT cells express the invariant $T$ cell receptor with the Va24-Ja18 gene rearrangement paired with the $\mathrm{V} \beta 11$ chain $^{39}$ and is restricted to recognizing lipid antigens: e.g. $\alpha$-galactosylceramide, abbreviated as $\alpha$-GalCer, and related $\alpha$-conformation glycolipids, which can be derived from bacterial genera including commensal gut Bacteriodes as well as Lyme disease Borrelia and other bacterial and other organisms, as below. Endogenous and selecting ligands, which are still being characterized, could be more directly involved in 'sterile inflammation' leading to autoimmunity). Lipids are presented by CD1d molecules on APCs. iNKT cells have also been referred to as type 1 NKT cells and classical NKT cells. In humans and mice, NKT cells in general have physiological roles in anti-tumor and anti-viral and other pathogen immune responses. Because of their ability to rapidly produce both Th1 and Th2 cytokines on antigenic stimulation, there has been interest in their role in supporting type 1 and type 2 cytokine responses from classical $\mathrm{CD} 4^{+} \mathrm{T}$ cells and for this reason have become a key area of research in autoimmunity ${ }^{40}$. yס T cells 
$\bar{\delta} \mathrm{T}$ cells are distinct from classical $\alpha \beta \mathrm{T}$ cells in that they express a $\mathrm{T}$ cell receptor which has been rearranged from the $Y$ and $\delta T$ cell receptor genes. They are much less abundant than $\alpha \beta$ T cells and there are much fewer segments at the $\gamma$ and $\delta$ gene loci for the $\gamma \delta \mathrm{T}$ cell to rearrange, with only 3 to $5 \mathrm{~V} \delta, \mathrm{D} \delta, \mathrm{J} \delta, \mathrm{V}_{Y}$ and $J y$ segments compared to 61 for the Ja segment of the $\alpha \beta T$ cell receptor ${ }^{18}$. Although $\gamma \delta T$ cells have much less diversity of their receptor segments when compared to $\alpha \beta T$ cells, they can be as diverse as $\alpha \beta T$ cells due to nucleotide insertions, and insertion of multiple $D \delta$ segments during rearrangement. In humans, the most common $y \delta$ T cell rearrangement found in blood is the $\mathrm{V}_{\gamma} 2 \mathrm{~V} \delta 2 \mathrm{~T}$ cell, also known differently through history as the $\mathrm{V}_{\gamma} 9 \mathrm{~V} \delta 2 \mathrm{~T}$ cell, which make up around $80 \%$ of all blood $ү \delta$ T cells. They do not recognize antigen in the context of MHC molecules. They likely recognize free antigen in a way similar to the B cell receptor, although recent work has shown that phosphoantigens can be presented to the Vү2Vס2 $\mathrm{T}$ cell receptor via an MHC-related membrane protein known as butyrophilin subfamily 3 member $A 1(B T N 3 A 1)^{41}$. Vү2Vס2 $T$ cells recognize phosphoantigens produced by a variety of bacteria, including mycobacteria, they rapidly expand and produce the proinflammatory cytokines TNF- $\alpha$ and IFN- $y^{42,43}$. A second common rearrangement is the $\mathrm{V} \delta 1 \mathrm{~T}$ cell which preferentially relocates to mucosal sites such as the skin and gut epithelium where they form a population of cells known as intra-epithelial lymphocytes and may play a role in surveillance destruction of stressed, pre-cancerous epithelial cells by engagement of the NK receptor NKG2D on epithelial cell ligands ${ }^{44}$. Although the Vס1 TCR ligands are yet to be characterized it is likely that endogenously produced stress molecules such as sulfatides may be implicated ${ }^{45}$. Vठ1 T cells are also found enriched and with an activated phenotype in peripheral sites of inflammation such as the rheumatoid synovium ${ }^{46}$ and could be responding to the expression of endogenous stress ligands at these sites.

\section{Mucosal-associated invariant T (MAIT) cells}

Despite their name, MAIT cells are a major subset of human peripheral blood T cells and are usually more frequent than y $\delta$ T cells $(\sim 5-10 \%$ versus $\sim 2-5 \%$ of peripheral blood T cells $)^{23}$. Their restriction by another non-polymorphic non-classical MHC molecule, $M R 1^{23}$, and reactivity to bacterial vitamin metabolite ligands presented by MR1 were recently defined ${ }^{24}$. Functionally, MAIT cells are mostly cytotoxic CD8 ${ }^{+}$cells with a smaller 
proportion being double negative (DN) for CD4 and CD8, and these produce large amounts of mostly pro-inflammatory cytokines ${ }^{23}$.

\section{Innate-like B (ILB) cells}

Just like their $\mathrm{T}$ cell siblings, B cells can possess regulatory and innate-like properties. Different innate-like B cells exist, potentially including B-1 (sometimes called B1) B cells, marginal zone (MZ) B cells, B10 cells and innate response activator (IRA) B cells depending on definition of 'innate ${ }^{28,48}$. As such, the B cell receptor of these cells may undergo minimal or no $\mathrm{V}(\mathrm{D}) \mathrm{J}$ rearrangement, with some receptors encoded in germline DNA, thereby causing them to fall into the innate-like category. So-called B-1 cells are able to produce natural $\operatorname{lgM}$, polyclonal antibodies found in health and in steady-state, with the functions of maintaining homeostasis and clearing apoptotic cells ${ }^{27}$. Marginal zone $B$ cells of the spleen can rapidly produce natural IgM after stimulation with Toll-like receptor ligands ${ }^{30}$, thereby acting as a first line against bacterial infection. B10 cells are named due to their ability to produce the anti-inflammatory cytokine IL-10 and may play a role similar to regulatory $T$ cells in inhibiting autoimmunity ${ }^{29}$. IRA $B$ cells are able to respond to bacterial pathogen-associated molecular patterns to produce granulocytemacrophage colony-stimulating factor (GM-CSF): Deletion of IRA B cells leads to reduced bacterial clearance and septic shock ${ }^{28}$.

Given the expanding technology involved in immunophenotyping, the number of different types of ILBs is expected to rise and it is likely that in the future we will learn more about their diverse roles in immune regulation and in frontline responses to infections. 


\section{Role of ILs in autoimmune diseases}

Generic versus disease-specific, and stage-specific, differences in immune cell phenotype and function have been defined in various autoimmune diseases. Current evidence for on balance positive or negative roles of particular IL types in specific autoimmune diseases is summarized below. Many ILs as well as other cytotoxic immune cells evolved to kill infected cells, amplified by pro-inflammatory cytokines, so it is not surprising that collateral damage could contribute to inflammation and ultimately autoimmune disease. Other ILs can modulate inflammation, so the local balance is likely critical. Ultimately, while some ILs and/or conventional T cell subsets may show generic changes in autoimmune and even other inflammatory diseases, they may not show specificity for a disease, stage or treatment in comparison to others. This remains a key question when considering hopefully specific therapies. Hence, below, we will describe distinct behaviors versus generic ones, where they have been defined.

\section{NK cells in autoimmunity}

The role of NK cells in autoimmunity is as yet unclear. Impairment of NK cell cytotoxicity has been implicated in autoimmune disease ${ }^{49}$. NK cell cytotoxicity and pro-inflammatory activities may at first seem deleterious, but the human CD56 bright subset, best known for secreting pro-inflammatory factors rather than NK cytotoxic activity, is associated with responses to biologics in multiple sclerosis (MS), and murine NK cells, at least, can secrete restorative neurotropic factors such as brain-derived neurotrophic factor (BDNF) and neurotrophin $3(\mathrm{NT}-3)^{50}$.

NK cells have also been shown to provide an important early source of IFN- $\gamma$, which enhances very late antigen-4 (VLA-4) expression on T cells and consequently migratory activity of pathogenic $\mathrm{T}$ cells in CNS autoimmunity ${ }^{51}$.

Regarding rheumatoid arthritis (RA), CD56 bright $\mathrm{NK}$ cells are enriched in RA synovia and respond to IL-12 and IL-15 by secreting IFN- $\gamma^{52}$. Furthermore, NK cells have been shown to communicate with and cause reciprocal activation of RA synovial fibroblasts by the actions of IL-6, IL-15 and IFN- ${ }^{53}$, and IL-22/TNFa-producing NK cells have been found in 
RA synovial fluid which also correlated with disease activity ${ }^{54}$. It may be that there is impairment in the cytotoxicity of NK cells with an increase in Th1 cytokine-producing NK cells in autoimmune diseases.

In Lyme arthritis, there appear to be elevated levels of activated IFN- $y$-producing CD56 ${ }^{\text {bright }}$ NK cells in synovial fluid, whether antibiotic resistant or not, suggesting that these cells contribute to excessive inflammation and immune dysregulation in joints ${ }^{55}$.

NK cytotoxicity was found to be significantly lower in patients specifically with adult-onset Still's disease than in healthy controls, but NK cell levels were comparable ${ }^{56}$. This appeared to be related to iNKT cells (see below).

One mechanism for IL involvement in autoimmune diseases maybe cytotoxicity: Granulysin-positive cells were elevated and brighter stained within patients with psoriatic arthritis (PsA) T cells as well as in the CD56 dim and CD56 bright NK subsets. Also, granulysin-mediated NK cell cytotoxicity was significantly higher from active phase PsA patients than patients in remission or in healthy controls ${ }^{57}$. These results suggest that granulysin-mediated NK cell cytotoxicity could contribute to psoriatic arthritis and other autoimmune diseases. However, NK activity in SLE patient blood can be reduced and less responsive to IFN $^{58,59}$.

\section{Other innate lymphoid cells in autoimmunity}

Newly-recognized ILCs may play complex roles in the pathogenesis of autoimmune diseases. Like their T cell cousins, ILC1 cells may contribute to inflammatory bowel disease $^{60}$, group 2 ILCs may promote asthma and allergy ${ }^{7,61}$, and ILC3 cells produce IL17 -related cytokines which have roles in the axial spondylo-arthropathies and psoriasis ${ }^{9}$. However, ILC3 are also important sources of homeostatic epithelial maintenance cytokine IL-22, for example in the gut, where it is protective against colitis ${ }^{62}$. Conclusive roles for the various ILC subsets may be more forthcoming as their characterization and our understanding improves rapidly in the near future. 


\section{NKT cells in autoimmunity}

In some autoimmune diseases models, NKT cells in general appear to be protective. For example, circulating iNKT cell numbers in patients with RA and other autoimmune diseases were reduced compared to healthy controls ${ }^{63}$. Furthermore, only a minority of iNKT cells from patients with autoimmune diseases responded to stimulation with the $\alpha$ GalCer suggesting there may be a defect in their function. An analysis of a number of autoimmune diseases found significantly reduced circulating iNKT cells compared to controls ${ }^{64}$. Treatments, such as glucocorticoids have the effect of reducing most circulating $T$ cell types but iNKT cells are relatively resistant ${ }^{65}$. Of course, circulating cell numbers do not well-reflect tissue-localisation. In any event. clinical information including concurrent treatments are desirable data in these studies, as it is well-known that concurrent treatment with multiple disease-modifying drugs including glucocorticoids is commonly a confounding factor in studies of patients with autoimmune diseases.

Regarding RA, circulating iNKT cells have been shown to have a Th1-biased phenotype when compared to controls and therefore may contribute to disease ${ }^{66,67}$. Also, iNKT cells have been shown to inhibit auto-reactive $B$ cells in a cell contact mediated manner via CD1 $d^{68}$. iNKT frequency is reduced in RA and was inversely correlated to the 28-joint Disease Activity Score (DAS28) ${ }^{67}$. Consistent with the above, iNKT in vitro proliferation was reduced in early RA, apparently independent of CD1d function. Indeed, in common with other ILs, iNKT can be stimulated by inflammatory cytokine combinations in the absence of lipid ligands or infections ${ }^{69}$. Molecular analysis showed that the iNKT-TCR repertoire is biased away from high-affinity lipid-reactive iNKT clones, specifically in early RA. Residual high-affinity iNKT cells had a Th1 bias in treatment-naïve subjects, but were more Th2-like from treated patients compared with the broad Th0-like profiles of all iNKT cells in controls ${ }^{67}$.

iNKT cells are significantly reduced in the peripheral blood of adult-onset Still's disease and have reduced proliferation in vitro compared to healthy controls, associated with excess pro-inflammatory cytokines and iNKT cell apoptosis ${ }^{56}$. Interestingly, iNKT cell deficiency correlated with both reduced NK cell activity and disease status. Finally, NK cytotoxicity, stimulated indirectly through iNKT cells by a-GalCer, was markedly reduced in Still's Disease compared to healthy controls ${ }^{56}$. 
In contrast to activated NK cells, which are uniformly present (see above), iNKT cells persist in antibiotic-responsive Lyme arthritis synovial fluid, but not in patients with antibiotic-refractory arthritis, implicating iNKT cells in immunomodulation of Lyme arthritis $^{55}$. Considerable model data is consistent with involvement of iNKT in protection against Lyme disease, due to iNKT stimulation by Borrelia glycolipids ${ }^{70-72}$.

Furthermore, there are other NKT subsets which may influence autoimmunity. CD1drestricted non-invariant NKT cells can be reactive towards sulfatide, an endogenous lipid, and have been found to have increased numbers in the gut of ulcerative colitis patients ${ }^{73}$ and non-invariant CD1d-restricted cells accumulate in the synovia of joints affected by $\mathrm{RA}^{74,75}$.

Although CD1 knockout (KO) mice lack major B cell defects, conversely, roles for B cells in iNKT cell human as well as murine development have been inferred ${ }^{76}$. This led to the observation that B cells are defective in iNKT homeostasis, associated with reduced CD1d expression. Interestingly, healthy donors' B cells treated with IFN- $\alpha$ when stimulated by anti-immunoglobulin also fail to support iNKT cell growth ${ }^{76}$. iNKT cell number and function were restored in SLE patients responding to anti-CD20 treatment, with normalization of CD1d on repopulated immature $B$ cells ${ }^{76}$. However, the expansion of innate-like $\mathrm{CD}^{+}$IL-10-producing B cells, now known as regulatory B cells, or 'Bregs', rather than NKT cells themselves, were reported to protect against experimental lupus by reducing CD4 T cell pro-inflammatory IL-17A and IFN- $\mathrm{Y}^{77}$.

In an interesting wrinkle on the above, however, the subset of SLAMF6 (Ly108)expressing iNKT cells can provide "pathogenic" help to B cells via IL-21 and can produce IL-17 in lupus prone mice ${ }^{78}$, emphasizing the dual potential of iNKT cells as well as other ILs in immunity in general. Therefore, care is certainly required when attempting to exploit such cell types in therapy. Indeed, in the same study, a-GalCer systemic activation of iNKT cells enhanced their helper activity for $\lg G$ autoantibody secretion by syngeneic $B$ cells in lupus-prone mouse models (NZB/W and B6.Sle $1 \mathrm{~b})^{78}$.

Symptoms of gut and joint inflammation in a murine spondyloarthritis ( $\mathrm{SpA}$ ) model induced by TNF over-expression were aggravated by crossing with iNKT KO mice. iNKT cells were activated during disease, linked to enrichment of inflammatory DCs with high CD1d, particularly at draining lymph nodes. These inflammatory DCs induced iNKT cells to produce immunomodulatory cytokines. A similar increase in CD1d levels was observed on DCs from patients with $\mathrm{SpA}^{79}$ 
iNKT cells have also been reported to play a protective role in osteoclastogenesis and inflammatory bone destruction in RA. a-GalCer-stimulated iNKT cells inhibited osteoclastogenesis partly via IFN-y. a-GalCer-treated mice showed less severe arthritis, synovial inflammatory cytokines and bone destruction. These positive effects of aGalCer were diminished in RA patients apparently due to iNKT cell impairment ${ }^{80}$.

Generally, inflammatory diseases have fewer detectable circulating iNKT cells suggesting a role in these conditions, whether reduction is due to a lower number of TCRs, exhaustion, apoptosis, or margination, for instance. Specificity, for iNKT versus classical $T$ cells is seen. However, specificity for RA versus other autoimmune diseases is generally not seen. Animal model data is mostly consistent with these clinical findings. These findings mostly ignore the harder to study Type 2 diverse NKT cells. Their role can be similarly inferred from specific involvement in autoimmunity, but there may be a stronger trend toward a protective role $^{81}$. Together, such findings warrant further investigation of the CD1d-restricted NKT cell populations in the context of autoimmune disease in general ${ }^{11}$.

\section{Y $\mathrm{T}$ cells in autoimmunity}

үठ T cells have recently been shown to play a major pathogenic role in a number of autoimmune diseases. Although memory antigen-specific $ү \delta \mathrm{T}$ cells have been described in certain infections, the $y \delta T$ cells that mediate autoimmunity are innate-like, responding to inflammatory cytokines, especially IL-23 in synergy with IL-1 $\beta, I L-1 \alpha$ or IL-18 in the absence of TCR activation ${ }^{82,83}$. Studies in experimental autoimmune encephalomyelitis $(E A E)$, a mouse model for multiple sclerosis have shown that $\gamma \delta T$ cells provide an important early source of IL-17 and IL-21 that promotes further IL-17A, IL-17F and GMCSF production by Th17 cells ${ }^{83}$. IL-17-producing $y \delta T$ cells have also been shown to have a pathogenic role in mouse models of psoriasis and have been detected in skin lesion of psoriasis patients ${ }^{19,84}$.

Regarding autoimmunity, $y \delta \mathrm{T}$ cells have been found to be approximately 10 -fold enriched relative to blood and to make up to $20-30 \%$ of the T cell population in early CNS lesions of multiple sclerosis ${ }^{85}$, where they are able to produce IL-17 to promote autoimmunity $^{86}$. That said, some $y \delta \mathrm{T}$ cells may be immunoregulatory via promotion of apoptosis of autoreactive $\alpha \beta$ T cells through Fas-FasL interaction ${ }^{87}$. Dermal-resident $\gamma \delta T$ 
cells provide a major source of IL-17 in mouse models of psoriasis ${ }^{19}$, although equivalent cells are rare in humans and it is thought that the main source of IL-17 in human skin diseases might be from ILCs, neutrophils and mast cells (reviewed by ${ }^{88}$ ). Furthermore, evidence for the involvement of $\gamma \delta T$ cells in RA and juvenile idiopathic arthritis (JIA) is conflicting, with some reporting that high proportions of $\gamma \delta T$ cells in JIA synovium contribute to TNF- $\alpha$ and IFN-y production in the joint ${ }^{89}$ and others suggesting that there is a change in the proportion of subtypes of $\gamma \delta \mathrm{T}$ cells in RA patients with $\mathrm{V} \gamma 2 \mathrm{~V} \delta 2 \mathrm{~T}$ cells being protective and $\mathrm{V}_{Y} 1 \mathrm{~V} \delta 1 \mathrm{~T}$ cells contributing to pathogenesis ${ }^{90}$. Clearly more work is needed to determine exactly which $ү \delta T$ cell subtypes are immune-protective and which contribute towards autoimmunity before $\gamma \delta \mathrm{T}$ cell therapies can be developed.

\section{MAIT cells in autoimmunity}

As described above, Mucosal-associated invariant T (MAIT) cells predominantly produce the pro-inflammatory cytokines IFN- $\gamma$ and IL-17. Despite some indication that MAIT cells can regulate MS Th1 responses ${ }^{91}$ their role in MS remains unclear ${ }^{25}$. MAIT are sometimes altered in autoimmune diseases ${ }^{26,92}$.

Clinically, MAIT cell levels were significantly higher in RA synovial fluid than in matched patient peripheral blood ${ }^{92}$. Furthermore, murine models of both collagen-induced arthritis (CIA) and of collagen antibody-induced arthritis (CAIA) are less severe in matched MR1 KO mice lacking MAIT cells versus normal replete controls ${ }^{93}$. Interestingly, in this study, MAIT cells became stimulated by IL-23 or IL-1 $\beta$ in the absence of T cell receptor stimuli, thus providing a general mechanism for sterile inflammation in the absence of infection.

Interestingly, conversely to NKT cells which are less susceptible to corticosteroids and may actually increase in proliferation ${ }^{65}$, MAIT cell suppression is caused by corticosteroids, which could complicate MAIT analysis in treated patients ${ }^{26}$. Furthermore, on these and other ILs as well as approximately $25 \%$ of adult human T cells, CD161 is down-regulated by recent activation ${ }^{26}$, although this is particularly relevant to MAIT cells as CD161 is regularly used to identify then. Studies which find a reduction in MAIT cells should take this finding into consideration as it may be reflecting a reduction of CD161 rather than a true reduction of MAIT cells. 


\section{Innate-like B cells in autoimmunity}

As with other innate lymphocytes, ILBs have been implicated in autoimmune diseases. Their diverse roles in both first-line response to bacterial infections, and natural IgM and $\mathrm{IL}-10$ secretion has led to recent findings that they may be altered or dysfunctional in some conditions.

Lupus is characterized by autoantibody production, and therefore how B cells lose tolerance is of great research interest. There have been many reports that pathogenic B1 cells in mice contribute to autoimmune models of lupus and lupus nephritis (reviewed by 94,95$)$. In humans, although not directly implicated, B-1 cells have been found in expanded numbers in lupus patient blood and are able to provide co-stimulation to $T$ cells by upregulating $\mathrm{CD} 86^{96}$.

B10 cells, which secrete IL-10, have been found in reduced numbers in peripheral blood of patients with type 1 diabetes $^{97}$, psoriasis ${ }^{98}$. In lupus, ex vivo stimulation found that B10 cells from patients produced more IL-10 than from controls ${ }^{99}$. Therefore, B10 cells and other ILBs may have different roles in different autoimmune diseases, and as with any other disease, the effect of treatments such as corticosteroids must be taken into consideration.

\section{Innate immune cells \& autoimmune disease biologic therapies}

The rapid increase in the number of biologic therapies for autoimmune diseases, coupled with the discovery of novel innate-like lymphocytes and innate lymphocyte cells, has led investigators to question how these drugs are affecting these ILs on a mechanistic level. This question remains largely unanswered.

There have, however, been studies looking at the effect of having increased or decreased numbers of NK cells in circulating peripheral blood samples and correlating these with response to treatment with various conventional disease-modifying anti-rheumatic drugs (DMARDs) and biologics. For instance, one group found that changes in the proportion of CD56 ${ }^{\text {bright }}$ CD $16{ }^{-}$NK cells predicted response to tocilizumab therapy in RA patients after 3 months ${ }^{100}$. The proportion and phenotype of other ILs might therefore be able to predict 
response to different treatments available, not only for RA but for other autoimmune diseases treated in the same manner.

Biologic drugs target the immune system by either mopping up inflammatory cytokines such as TNF- $\alpha$, IL-6, IL-17A, or by abrogating the adaptive immune response via $B$ cell reduction therapy or $\mathrm{T}$ cell co-stimulation blockade. That said, little is known about the modification of the newer ILCs and innate-like lymphocytes. There is, however, much interest in potent and specific iNKT ligands such as $\alpha$-GalCer in the application of cancer immunotherapy and immunomodulation of autoimmune disease (as reviewed by ${ }^{12}$ ). For instance, in a mouse model, administration of $\alpha$-GalCer reduced the occurrence of experimental autoimmune myasthenia gravis (EAMG) in susceptible animals from $91 \%$ to $30 \%{ }^{13,101}$.

Remarkably, a single dose of the iNKT ligand a-GalCer, and even the Th1-polarizing analog $\alpha-C-G a l C e r$ given to DBA/1 mice during the induction phase of collagen-induced arthritis (CIA) had therapeutic efficacy ${ }^{102}$. Neutralization of IFN-y early resulted in partial improvement of arthritis, whereas blockade later resulted in more rapid improvement.

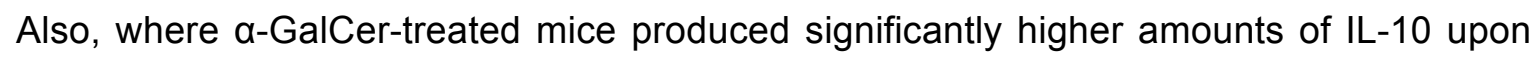
systemic anti-CD3 stimulation compared with PBS controls, T cells from $\alpha-C-G a l C e r-$ treated mice, by contrast, produced lower levels of cytokines, suggesting different mechanisms. Hence, CIA responded to immunomodulatory effects of iNKT cells stimulated with different lipid ligands. Consistent with these results, $\alpha-G a l C e r$ also significantly reduced the severity of CIA in another model when administered to arthritic mice ${ }^{103,104}$. Therefore, in mouse models of autoimmunity, in vivo administration of iNKT ligands can ameliorate autoimmune disease, suggesting a role of NKT cells in immunoregulation of such diseases. However, therapy is of course distinct from physiological involvement. 


\section{Mouse versus Man! (A call-out 'Box')}

While much has been learnt from mouse and other animal models, the murine and human immune systems have evolved to handle only a partially overlapping spectrum of infectious organisms.

While both of course mammals, mouse physiology is clearly very different to humans and certain organ systems are particularly different, such as skin, with not just fur versus limited hair, but major differences in immune components. For instance, healthy mouse skin contains large proportions of $ү \delta \mathrm{T}$ cells, originally called 'dendritic epidermal cells' (DECs), whereas human skin contains more $\alpha \beta \mathrm{T}$ cells than the peripheral blood. Nonetheless, overall similarities are underscored by often similar, although far from identical, etiologies of autoimmunity in man (for example: RA versus other arthropathies, SLE, T1D; different inflammatory bowel diseases) and mouse (collagen-induced arthritis, lupus-like and NOD mouse strains, DSS and oxazalone colitis models).

Furthermore, human autoimmune diseases reflect years or even decades of chronic inflammation in a much larger longer-lived organism with variable lifestyles. Comorbidities, previous pathogen exposure histories (compared to standard animal facility 'Specific Pathogen Free, SPF, mice and other model animals), and genetic heterogeneity all contribute to the limits between model and clinical diseases. Our lack of knowledge of the aetiology of most clinical autoimmune diseases ensures that models are at best not optimal. Nonetheless, much had been learned from in vivo model studies and some has translated into effective treatments for autoimmune diseases.

Like Art (as pointed out by Pablo Picasso), an autoimmune model "is a lie that tells the truth"! 
Impacting Autoimmunity through ILs (A call-out 'Box'/ Table)

Some innate lymphocytes can be directly targeted with varying levels of specificity by various small molecules and/or biologics. Current and future targets and agents potential selectivity are listed below:

\begin{tabular}{|c|c|c|c|c|}
\hline Target Cell & Target Molecule(s) & Target Selectivity & Possible outcome & Refs. \\
\hline NK cells & KIRs & $\begin{array}{l}\text { Moderate } \\
\text { (NK/NKT) - High }\end{array}$ & $\begin{array}{l}\text { Safe, objective } \\
\text { responses in } \\
\text { cancer trials }\end{array}$ & 105 \\
\hline ILC1 & NKRs \& C-lectins & $\begin{array}{l}\text { Moderate: } \\
\text { NK/NKT }\end{array}$ & $\begin{array}{l}\text { Low cytotoxicity } \\
\text { No clinical data }\end{array}$ & 1 \\
\hline iNKT cells & $\begin{array}{l}\text { iNKT TCR } \\
\text { activation: mAb } \\
\text { Glycolipid ligands } \\
\text { Shared NKRs }\end{array}$ & $\begin{array}{l}\text { High } \\
\text { High } \\
\text { Moderate:NK/NKT }\end{array}$ & $\begin{array}{l}\text { Pos. \& neg. roles } \\
\text { Safe, objective } \\
\text { responses in } \\
\text { cancer trials }\end{array}$ & $\begin{array}{l}14,15,103 \\
16,17\end{array}$ \\
\hline Yठ T cells & Yठ TCR & High (subsets) & $\begin{array}{l}\text { Pos. \& neg. roles } \\
\text { Safe, objective } \\
\text { responses in } \\
\text { cancer trials }\end{array}$ & 106 \\
\hline MAIT cells & $\begin{array}{l}\text { Adoptive transfer } \\
\text { or increase levels }\end{array}$ & Relatively High & $\begin{array}{l}\text { Pos. \& neg. roles } \\
\text { No clinical data }\end{array}$ & 91 \\
\hline
\end{tabular}

Table 2: Targeting Innate Lymphocytes: Innate Lymphocyte subsets and ability to target, potential relevance to autoimmune diseases (AIDs) and safety in other indications (if known). 


\section{E. Conclusions \& Prospects for Targeting Innate Lymphocytes in Autoimmunity}

In summary, the immune system contributes to protective inflammation, but this can also become chronic in disease through chronic stimulation with exogenous or self (auto-) antigens (Figure 1). Like TNF and other effector molecules in autoimmune diseases, proinflammatory innate lymphocytes likely contribute and may be appropriate targets to ameliorate various autoimmune diseases. Conversely, primarily regulatory cells in the context of autoimmunity, such as in the majority of cases of NKT cells, may offer targets for agonism in autoimmune diseases. While heterogeneous, innate lymphocytes are far less diverse than adaptive B and T cells, which have been successfully, albeit broadly, targeted. Rituximab is a good example. Hence, innate lymphocyte subsets represent attractive targets (Table 2), where a therapeutic window between efficacy and safety, always a challenge in autoimmune prone individuals, can be found. Particularly in autoimmunity, ability to 'switch off' the therapy urgently in cases where acute infections or exacerbations occur would provide added confidence to target specific subsets. For example, small molecules typically have short half-life in vivo, but many antibody-based antibodies can stay in circulation for weeks. Specific anti-antibodies might be used to deplete therapeutic antibodies when unwanted side-effects appeared. Increasing interest in gene (including editing somatic tissues with clustered regularly-interspaced short palindromic repeats (CRISPR) associated protein-9 and other approaches, reviewed by

${ }^{107}$ ) and cell therapies in autoimmunity as well as other diseases increases the need for 'kill switches' for both approaches. NK, iNKT, and $\gamma \delta \mathrm{T}$ have been safely targeted in cancer patients, with evidence for objective responses in some of these trials in all 3 cases $(35,108-109)$.

Elucidating the different positive and negative roles of innate lymphocytes in autoimmune diseases offers rheumatologists plenty of likely rewarding challenges in the next few years. 


\section{Legends:}

Figure 1: Innate Lymphocytes can initiate protective and destructive immune responses.

Innate Lymphocytes (I) can rapidly produce substantial amounts of pro- or antiinflammatory cytokines (and chemokines) upon stimulation. Some IL respond to antigen presenting cells expressing monomorphic non-classical MHC: MR1 for MAIT and CD1d for NKT cells, possibly butyrophilin 3A1 (CD277) for Vy9Vס2+ T cells $^{41}$. Others respond to stress-induced or other molecules (e.g. ILC) and even possibly soluble ligands. They can also often exert direct cytotoxic activity (not shown for clarity).

Pro-inflammatory mediators* include TNF- $\alpha$ IL-17, IL-23, IL-1 $\beta$, and TGF- $\beta$ (which can be pro-Th17 or anti-inflammatory depending upon other cytokine context), further amplified by IL-33 or SST2 in some diseases. Anti-inflammatory cytokines ${ }^{\#}$ include IL-10 and TGF- $\beta$.

Pro-inflammatory cytokines lead to recruitment and activation of phagocytic neutrophils and macrophages, which can cause damage to local tissue. Such damage releases antigens which can be presented to adaptive classical $\mathrm{T}$ cells (II) which particularly in a pro-inflammatory milieu leads to Th1 \&/or Th17 responses which further damage tissue (III). Acute responses of this nature can clear infected or damaged tissue leading to healing responses. Chronic inflammation promotes development of autoimmunity in predisposed individuals. 


\section{Figure 2: 'Yin and yang' of immunity.}

What is needed and can be essential for protective and sterilising immunity in cancer and infectious diseases can alternatively be deleterious in chronic inflammation and autoimmunity. Conversely, suppressing and tolerising responses, necessary to terminate successful pathogen responses and limit tissue destruction, can prevent pathogen clearance or tumor surveillance and lead to disease progression. Therefore, local immune balance is critical to overall health. Altering a too suppressive balance can lead to anti-tumor responses, exploited with checkpoint inhibitor blockade with some autoimmune sequelae, which can be acceptable in advanced cancer and increasingly treatable. Finally, the loss of immune balance in some autoimmune diseases may contribute to tumor escape from immune control, as where IBD and esophagitis leads to cancer. IBD: inflammatory bowel disease.

\section{Acknowledgements}

The authors thank their MCCIR, IIR and other colleagues for stimulating discussions and apologize to those whose work was not fully cited. MAE supported by an unrestricted grant to MCCIR by AstraZeneca and GlaxoSmithKline and NIH grant CA170194. GCT is supported by Al42269. KHGM is supported by Science Foundation Ireland PI/11/1036. DE received support from Scientific Research Flanders (FWO), by a concerted research action grant of the Research Council of Ghent University, by InterUniversity Attraction Pole (IUAP) grant Devrepair from the Belspo Agency (project P7/07) and EU Seventh Framework Programme (EC-GA $\mathrm{n}^{\circ} 305266$ 'MIAMl'). $\mathrm{DE}$ is a member of a Multidisciplinary Research Platform of Ghent University. BM received an MCCIR Clinical Training Fellowship. MAE is employed by Agenus Inc., a company developing cancer immunotherapies. Other authors have no relevant conflicts of interest. 
Running title: A rheumatologist's unconventional lymphocytes

\section{Bibliography}

1. Spits, H. \& Di Santo, J. P. The expanding family of innate lymphoid cells: regulators and effectors of immunity and tissue remodeling. Nat. Immunol. 12, 2127 (2010).

2. Gaffen, S. L., Jain, R., Garg, A. V \& Cua, D. J. The IL-23-IL-17 immune axis: from mechanisms to therapeutic testing. Nat. Rev. Immunol. 14, 585-600 (2014).

3. Awada, A. et al. Potential involvement of the IL-33-ST2 axis in the pathogenesis of primary Sjogren's syndrome. Ann. Rheum. Dis. 73, 1259-63 (2014).

4. Walker, J. A., Barlow, J. L. \& McKenzie, A. N. J. Innate lymphoid cells--how did we miss them? Nat. Rev. Immunol. 13, 75-87 (2013).

5. Fogel, L. A., Yokoyama, W. M. \& French, A. R. Natural killer cells in human autoimmune disorders. Arthritis Res. Ther. 15, 216 (2013).

6. Sun, J. C. \& Lanier, L. L. NK cell development, homeostasis and function: parallels with $\mathrm{CD}^{+}$T cells. Nat. Rev. Immunol. 11, 645-57 (2011).

7. Martinez-Gonzalez, I., Steer, C. A. \& Takei, F. Lung ILC2s link innate and adaptive responses in allergic inflammation. Trends Immunol. 36, 189-95 (2015).

8. Crellin, N. K., Trifari, S., Kaplan, C. D., Cupedo, T. \& Spits, H. Human NKp44+IL$22+$ cells and LTi-like cells constitute a stable RORC+ lineage distinct from conventional natural killer cells. J. Exp. Med. 207, 281-90 (2010).

9. Teunissen, M. B. M. et al. Composition of innate lymphoid cell subsets in the human skin: enrichment of $\mathrm{NCR}(+)$ ILC3 in lesional skin and blood of psoriasis patients. J. Invest. Dermatol. 134, 2351-60 (2014).

10. Hegde, S., Fox, L., Wang, X. \& Gumperz, J. E. Autoreactive natural killer T cells: promoting immune protection and immune tolerance through varied interactions with myeloid antigen-presenting cells. Immunology 130, 471-83 (2010).

11. Simoni, Y., Diana, J., Ghazarian, L., Beaudoin, L. \& Lehuen, a. Therapeutic manipulation of natural killer (NK) T cells in autoimmunity: are we close to reality? Clin. Exp. Immunol. 171, 8-19 (2013).

12. Macho-Fernandez, E. \& Brigl, M. The Extended Family of CD1d-Restricted NKT 
Cells: Sifting through a Mixed Bag of TCRs, Antigens, and Functions. Front. Immunol. 6, 362 (2015).

13. Van Kaer, L. Natural killer T cells as targets for immunotherapy of autoimmune diseases. Immunol. Cell Biol. 82, 315-322 (2004).

14. Coppieters, K. et al. NKT cells: manipulable managers of joint inflammation. Rheumatology (Oxford). 46, 565-71 (2007).

15. Miellot-Gafsou, A. et al. Early activation of invariant natural killer T cells in a rheumatoid arthritis model and application to disease treatment. Immunology 130, 296-306 (2010).

16. Miyake, S. \& Yamamura, T. Therapeutic potential of glycolipid ligands for natural killer (NK) T cells in the suppression of autoimmune diseases. Curr. Drug Targets. Immune. Endocr. Metabol. Disord. 5, 315-22 (2005).

17. Lalazar, G., Preston, S., Zigmond, E., Ben Yáacov, A. \& Ilan, Y. Glycolipids as immune modulatory tools. Mini Rev. Med. Chem. 6, 1249-53 (2006).

18. Girardi, M. Immunosurveillance and immunoregulation by gammadelta $T$ cells. $J$. Invest. Dermatol. 126, 25-31 (2006).

19. Cai, Y. et al. Pivotal Role of Dermal IL-17-Producing yס T Cells in Skin Inflammation. Immunity 35, 596-610 (2011).

20. Willcox, C. R. et al. Cytomegalovirus and tumor stress surveillance by binding of a human $ү \delta \mathrm{T}$ cell antigen receptor to endothelial protein $\mathrm{C}$ receptor. Nat. Immunol. 13, 872-9 (2012).

21. Steinle, A., Groh, V. \& Spies, T. Diversification, expression, and gamma delta T cell recognition of evolutionarily distant members of the MIC family of major histocompatibility complex class I-related molecules. Proc. Natl. Acad. Sci. U. S. A. 95, 12510-5 (1998).

22. Shimura, E. et al. Epidermal gammadelta T cells sense precancerous cellular dysregulation and initiate immune responses. Int. Immunol. 22, 329-40 (2010).

23. Le Bourhis, L., Mburu, Y. K. \& Lantz, O. MAIT cells, surveyors of a new class of antigen: development and functions. Curr. Opin. Immunol. 25, 174-80 (2013). 
24. Kjer-Nielsen, L. et al. MR1 presents microbial vitamin B metabolites to MAIT cells. Nature 491, 717-23 (2012).

25. Treiner, E. \& Liblau, R. S. Mucosal-Associated Invariant T Cells in Multiple Sclerosis: The Jury is Still Out. Front. Immunol. 6, 503 (2015).

26. Hinks, T. S. MAIT cells in autoimmunity, immune mediated diseases and airways disease. Immunology (2016). doi:10.1111/imm.12582

27. Kaveri, S. V, Silverman, G. J. \& Bayry, J. Natural IgM in immune equilibrium and harnessing their therapeutic potential. J. Immunol. 188, 939-45 (2012).

28. Rauch, P. J. et al. Innate response activator B cells protect against microbial sepsis. Science 335, 597-601 (2012).

29. Iwata, Y. et al. Characterization of a rare IL-10-competent B-cell subset in humans that parallels mouse regulatory B10 cells. Blood 117, 530-41 (2011).

30. Rubtsov, A. V et al. TLR agonists promote marginal zone B cell activation and facilitate T-dependent IgM responses. J. Immunol. 180, 3882-8 (2008).

31. Kärre, K., Ljunggren, H. G., Piontek, G. \& Kiessling, R. Selective rejection of H-2deficient lymphoma variants suggests alternative immune defence strategy. Nature 319, 675-678 (1986).

32. Spits, H. et al. Innate lymphoid cells--a proposal for uniform nomenclature. Nat. Rev. Immunol. 13, 145-9 (2013).

33. Kawano, T. et al. CD1d-restricted and TCR-mediated activation of valpha14 NKT cells by glycosylceramides. Science $\mathbf{2 7 8 , 1 6 2 6 - 9}$ (1997).

34. van Dommelen, S. L. H., Tabarias, H. A., Smyth, M. J. \& Degli-Esposti, M. A. Activation of natural killer (NK) T cells during murine cytomegalovirus infection enhances the antiviral response mediated by NK cells. J. Virol. $\mathbf{7 7 , 1 8 7 7 - 8 4}$ (2003).

35. Exley, M. A. et al. Developing understanding of the roles of CD1d-restricted T cell subsets in cancer: reversing tumor-induced defects. Clin. Immunol. 140, 184-95 (2011).

36. Exley, M. A. \& Koziel, M. J. To be or not to be NKT: natural killer T cells in the liver. 
Hepatology 40, 1033-40 (2004).

37. Chen, H. \& Paul, W. E. Cultured NK1.1+ CD4+ T cells produce large amounts of IL-4 and IFN-gamma upon activation by anti-CD3 or CD1. J. Immunol. 159, 22409 (1997).

38. Godfrey, D. I., MacDonald, H. R., Kronenberg, M., Smyth, M. J. \& Van Kaer, L. NKT cells: what's in a name? Nat. Rev. Immunol. 4, 231-7 (2004).

39. Dellabona, P., Padovan, E., Casorati, G., Brockhaus, M. \& Lanzavecchia, A. An invariant $\mathrm{V}$ alpha $24-\mathrm{J}$ alpha $\mathrm{Q} / \mathrm{V}$ beta $11 \mathrm{~T}$ cell receptor is expressed in all individuals by clonally expanded CD4-8- T cells. J. Exp. Med. 180, 1171-6 (1994).

40. Hammond, K. J. L. \& Godfrey, D. I. NKT cells: Potential targets for autoimmune disease therapy? Tissue Antigens 59, 353-363 (2002).

41. Harly, C. et al. Key implication of CD277/butyrophilin-3 (BTN3A) in cellular stress

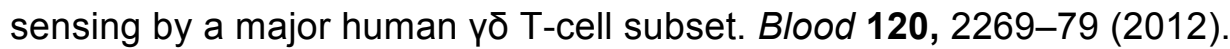

42. Lang, F. et al. Early activation of human $\mathrm{V}$ gamma $9 \mathrm{~V}$ delta $2 \mathrm{~T}$ cell broad cytotoxicity and TNF production by nonpeptidic mycobacterial ligands. J. Immunol. 154, 5986-94 (1995).

43. Wang, L., Das, H., Kamath, A. \& Bukowski, J. F. Human V gamma 2 V delta $2 \mathrm{~T}$ cells produce IFN-gamma and TNF-alpha with an on/off/on cycling pattern in response to live bacterial products. J. Immunol. 167, 6195-201 (2001).

44. Pardoll, D. M. Immunology. Stress, NK receptors, and immune surveillance. Science 294, 534-6 (2001).

45. Luoma, A. M. et al. Crystal structure of Vס1 T cell receptor in complex with CD1dsulfatide shows MHC-like recognition of a self-lipid by human $ү \delta$ T cells. Immunity 39, 1032-42 (2013).

46. Bucht, A. et al. T cell receptor diversity and activation markers in the $\mathrm{V}$ delta 1 subset of rheumatoid synovial fluid and peripheral blood T lymphocytes. Eur. J. Immunol. 22, 567-74 (1992).

47. Sattler, A., Dang-Heine, C., Reinke, P. \& Babel, N. IL-15 dependent induction of IL18 secretion as a feedback mechanism controlling human MAIT-cell effector functions. Eur. J. Immunol. 45, 2286-98 (2015). 
48. Bouaziz, J.-D., Yanaba, K. \& Tedder, T. F. Regulatory B cells as inhibitors of immune responses and inflammation. Immunol. Rev. 224, 201-14 (2008).

49. Yabuhara, A. et al. A killing defect of natural killer cells as an underlying immunologic abnormality in childhood systemic lupus erythematosus. J. Rheumatol. 23, 171-7 (1996).

50. Gandhi, R., Laroni, A. \& Weiner, H. L. Role of the innate immune system in the pathogenesis of multiple sclerosis. J. Neuroimmunol. 221, 7-14 (2010).

51. Dungan, L. S., McGuinness, N. C., Boon, L., Lynch, M. A. \& Mills, K. H. G. Innate IFN-y promotes development of experimental autoimmune encephalomyelitis: a role for NK cells and M1 macrophages. Eur. J. Immunol. 44, 2903-17 (2014).

52. Dalbeth, N. \& Callan, M. F. C. A subset of natural killer cells is greatly expanded within inflamed joints. Arthritis Rheum. 46, 1763-72 (2002).

53. Chan, A. et al. Mediation of the proinflammatory cytokine response in rheumatoid arthritis and spondylarthritis by interactions between fibroblast-like synoviocytes and natural killer cells. Arthritis Rheum. 58, 707-17 (2008).

54. Ren, J., Feng, Z., Lv, Z., Chen, X. \& Li, J. Natural killer-22 cells in the synovial fluid of patients with rheumatoid arthritis are an innate source of interleukin 22 and tumor necrosis factor-a. J. Rheumatol. 38, 2112-8 (2011).

55. Katchar, K., Drouin, E. E. \& Steere, A. C. Natural killer cells and natural killer T cells in Lyme arthritis. Arthritis Res. Ther. 15, R183 (2013).

56. Lee, S.-J. et al. Natural killer T cell deficiency in active adult-onset Still's Disease: correlation of deficiency of natural killer T cells with dysfunction of natural killer cells. Arthritis Rheum. 64, 2868-77 (2012).

57. Massari, D. et al. Analysis of granulysin-mediated cytotoxicity in peripheral blood of patients with psoriatic arthritis. Rheumatol. Int. 32, 2777-84 (2012).

58. Tsokos, G. C., Rook, A. H., Djeu, J. Y. \& Balow, J. E. Natural killer cells and interferon responses in patients with systemic lupus erythematosus. Clin. Exp. Immunol. 50, 239-45 (1982).

59. Spada, R., Rojas, J. M. \& Barber, D. F. Recent findings on the role of natural killer cells in the pathogenesis of systemic lupus erythematosus. J. Leukoc. Biol. 98, 
479-87 (2015).

60. Bernink, J. H. et al. Human type 1 innate lymphoid cells accumulate in inflamed mucosal tissues. Nat. Immunol. 14, 221-9 (2013).

61. Christianson, C. A. et al. Persistence of asthma requires multiple feedback circuits involving type 2 innate lymphoid cells and IL-33. J. Allergy Clin. Immunol. 136, 5968.e14 (2015).

62. Mielke, L. A. et al. Retinoic acid expression associates with enhanced IL-22 production by $\gamma \delta \mathrm{T}$ cells and innate lymphoid cells and attenuation of intestinal inflammation. J. Exp. Med. 210, 1117-24 (2013).

63. Kojo, S., Adachi, Y., Keino, H., Taniguchi, M. \& Sumida, T. Dysfunction of T cell receptor AV24AJ18+, BV11+ double-negative regulatory natural killer T cells in autoimmune diseases. Arthritis Rheum. 44, 1127-38 (2001).

64. van der Vliet, H. J. et al. Circulating V(alpha24+) Vbeta11+ NKT cell numbers are decreased in a wide variety of diseases that are characterized by autoreactive tissue damage. Clin. Immunol. 100, 144-8 (2001).

65. Milner, J. D. et al. Differential responses of invariant $\vee$ alpha $24 \mathrm{~J}$ alpha $Q T$ cells and MHC class II-restricted CD4+ T cells to dexamethasone. J. Immunol. 163, 2522-9 (1999).

66. Linsen, L. et al. Peripheral blood but not synovial fluid natural killer T cells are biased towards a Th1-like phenotype in rheumatoid arthritis. Arthritis Res. Ther. 7, R493-502 (2005).

67. Mansour, S. et al. Structural and Functional Changes of the Invariant NKT Clonal Repertoire in Early Rheumatoid Arthritis. J. Immunol. 195, 5582-91 (2015).

68. Yang, J.-Q., Wen, X., Kim, P. J. \& Singh, R. R. Invariant NKT cells inhibit autoreactive B cells in a contact- and CD1d-dependent manner. J. Immunol. 186, 1512-20 (2011).

69. Exley, M. A., Wilson, B. \& Balk, S. P. Isolation and functional use of human NKT cells. Curr. Protoc. Immunol. Chapter 14, Unit 14.11 (2010).

70. Kumar, H., Belperron, A., Barthold, S. W. \& Bockenstedt, L. K. Cutting edge: CD1d deficiency impairs murine host defense against the spirochete, Borrelia burgdorferi. 
J. Immunol. 165, 4797-801 (2000).

71. Kinjo, Y. et al. Natural killer T cells recognize diacylglycerol antigens from pathogenic bacteria. Nat. Immunol. 7, 978-86 (2006).

72. Tupin, E. et al. NKT cells prevent chronic joint inflammation after infection with Borrelia burgdorferi. Proc. Natl. Acad. Sci. U. S. A. 105, 19863-8 (2008).

73. Fuss, I. J. et al. IL-13Ra2-bearing, type II NKT cells reactive to sulfatide selfantigen populate the mucosa of ulcerative colitis. Gut 63, 1728-36 (2014).

74. Gutowska-Owsiak, D., Birchall, M. A., Moots, R. J., Christmas, S. E. \& Pazmany, L. Proliferatory defect of invariant population and accumulation of non-invariant CD1d-restricted natural killer T cells in the joints of RA patients. Mod. Rheumatol. 24, 434-42 (2014).

75. Gutowska-Owsiak, D., Birchall, M. A., Moots, R. J., Christmas, S. E. \& Pazmany, L. Expanded population of CD1d-restricted Va24+ cells in a patient with active rheumatoid arthritis. Clin. Immunol. 150, 140-2 (2014).

76. Bosma, A., Abdel-Gadir, A., Isenberg, D. A., Jury, E. C. \& Mauri, C. Lipid-antigen presentation by $C D 1 d(+) B$ cells is essential for the maintenance of invariant natural killer T cells. Immunity 36, 477-90 (2012).

77. Baglaenko, Y. et al. Suppression of autoimmunity by CD5(+) IL-10-producing B cells in lupus-prone mice. Genes Immun. 16, 311-20

78. Tang, X. et al. Ly108 expression distinguishes subsets of invariant NKT cells that help autoantibody production and secrete IL-21 from those that secrete IL-17 in lupus prone NZB/W mice. J. Autoimmun. 50, 87-98 (2014).

79. Jacques, P. et al. Invariant natural killer T cells are natural regulators of murine spondylarthritis. Arthritis Rheum. 62, 988-99 (2010).

80. Jin, H.-M. et al. Dysregulated Osteoclastogenesis Is Related to Natural Killer T Cell Dysfunction in Rheumatoid Arthritis. Arthritis Rheumatol. (Hoboken, N.J.) 67, 2639-50 (2015).

81. Kumar, V. \& Delovitch, T. L. Different subsets of natural killer T cells may vary in their roles in health and disease. Immunology 142, 321-36 (2014). 
82. Lalor, S. J. et al. Caspase-1-processed cytokines IL-1beta and IL-18 promote IL-17 production by gammadelta and CD4 T cells that mediate autoimmunity. $J$. Immunol. 186, 5738-48 (2011).

83. Sutton, C. E. et al. Interleukin-1 and IL-23 induce innate IL-17 production from gammadelta T cells, amplifying Th17 responses and autoimmunity. Immunity 31, 331-41 (2009).

84. Laggner, U. et al. Identification of a novel proinflammatory human skin-homing Vү9Vס2 T cell subset with a potential role in psoriasis. J. Immunol. 187, 2783-93 (2011).

85. Wucherpfennig, K. W. et al. Gamma delta T-cell receptor repertoire in acute multiple sclerosis lesions. Proc. Natl. Acad. Sci. U. S. A. 89, 4588-92 (1992).

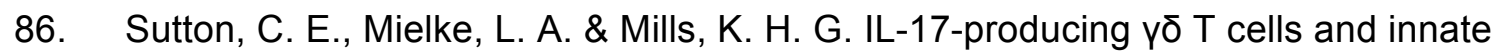
lymphoid cells. Eur. J. Immunol. 42, 2221-31 (2012).

87. Ponomarev, E. D. \& Dittel, B. N. Gamma delta T cells regulate the extent and duration of inflammation in the central nervous system by a Fas ligand-dependent mechanism. J. Immunol. 174, 4678-87 (2005).

88. Keijsers, R. R. M. C., Joosten, I., van Erp, P. E. J., Koenen, H. J. P. M. \& van de Kerkhof, P. C. M. Cellular sources of IL-17 in psoriasis: a paradigm shift? Exp. Dermatol. 23, 799-803 (2014).

89. Bendersky, A. et al. Cellular interactions of synovial fluid $ү \delta ~ T$ cells in juvenile idiopathic arthritis. J. Immunol. 188, 4349-59 (2012).

90. Bank, I. et al. gammadelta T cell subsets in patients with arthritis and chronic neutropenia. Ann. Rheum. Dis. 61, 438-43 (2002).

91. Miyazaki, Y., Miyake, S., Chiba, A., Lantz, O. \& Yamamura, T. Mucosal-associated invariant T cells regulate Th1 response in multiple sclerosis. Int. Immunol. 23, 52935 (2011).

92. Cho, Y.-N. et al. Mucosal-associated invariant T cell deficiency in systemic lupus erythematosus. J. Immunol. 193, 3891-901 (2014).

93. Chiba, A. et al. Mucosal-associated invariant T cells promote inflammation and exacerbate disease in murine models of arthritis. Arthritis Rheum. 64, 153-61 
(2012).

94. Sang, A., Zheng, Y.-Y. \& Morel, L. Contributions of B cells to lupus pathogenesis. Mol. Immunol. 62, 329-338 (2014).

95. Duan, B. \& Morel, L. Role of B-1a cells in autoimmunity. Autoimmun. Rev. 5, 4038 (2006).

96. Griffin, D. O. \& Rothstein, T. L. A small CD11b(+) human B1 cell subpopulation stimulates T cells and is expanded in lupus. J. Exp. Med. 208, 2591-8 (2011).

97. Deng, C. et al. Altered Peripheral B-Lymphocyte Subsets in Type 1 Diabetes and Latent Autoimmune Diabetes in Adults. Diabetes Care 39, 434-40 (2016).

98. Hayashi, M. et al. IL-10-producing regulatory B cells are decreased in patients with psoriasis. J. Dermatol. Sci. 81, 93-100 (2016).

99. Amel Kashipaz, M. R. et al. Assessment of Be1 and Be2 cells in systemic lupus erythematosus indicates elevated interleukin-10 producing CD5+ B cells. Lupus 12, 356-63 (2003).

100. Daïen, C. I. et al. High levels of natural killer cells are associated with response to tocilizumab in patients with severe rheumatoid arthritis. Rheumatology (Oxford). 18 (2014). doi:10.1093/rheumatology/keu363

101. Wang, Y. H., Jia, J. C., Liu, G. \& Wang, Y. F. Research on the influence of $\alpha-$ GalCer activating experimental autoimmune myasthenia gravis mice NKT cells at different times on myasthenia gravis. J. Biol. Regul. Homeost. Agents 29, 195-200

102. Chiba, A. et al. Suppression of collagen-induced arthritis by natural killer $T$ cell activation with $\mathrm{OCH}$, a sphingosine-truncated analog of alpha-galactosylceramide. Arthritis Rheum. 50, 305-13 (2004).

103. Horikoshi, M. et al. Activation of Invariant NKT cells with glycolipid ligand $\alpha-$ galactosylceramide ameliorates glucose-6-phosphate isomerase peptide-induced arthritis. PLoS One 7, e51215 (2012).

104. Coppieters, K. et al. A single early activation of invariant NK T cells confers longterm protection against collagen-induced arthritis in a ligand-specific manner. $J$. Immunol. 179, 2300-9 (2007). 
Running title: A rheumatologist's unconventional lymphocytes

105. Walsh, C. E. et al. Differential expression of NK receptors CD94 and NKG2A by T cells in rheumatoid arthritis patients in remission compared to active disease. PLoS One 6, e27182 (2011).

106. Wu, Y.-L. et al. үס T cells and their potential for immunotherapy. Int. J. Biol. Sci. 10, 119-35 (2014).

107. Chen, Y. Y. Efficient Gene Editing in Primary Human T Cells. Trends Immunol. 36, 667-9 (2015).

108. Cheng M, Chen Y, Xiao W, Sun R, Tian Z. NK cell-based immunotherapy for malignant diseases. Cell Mol Immunol. 10, 230-52 (2013).

109. Buccheri S, Guggino G, Caccamo N, Li Donni P, Dieli F. Efficacy and safety of $ү \delta T$ cell-based tumor immunotherapy: a meta-analysis. J Biol Regul Homeost Agents. 28, 81-90 (2014). 
Fig. 1

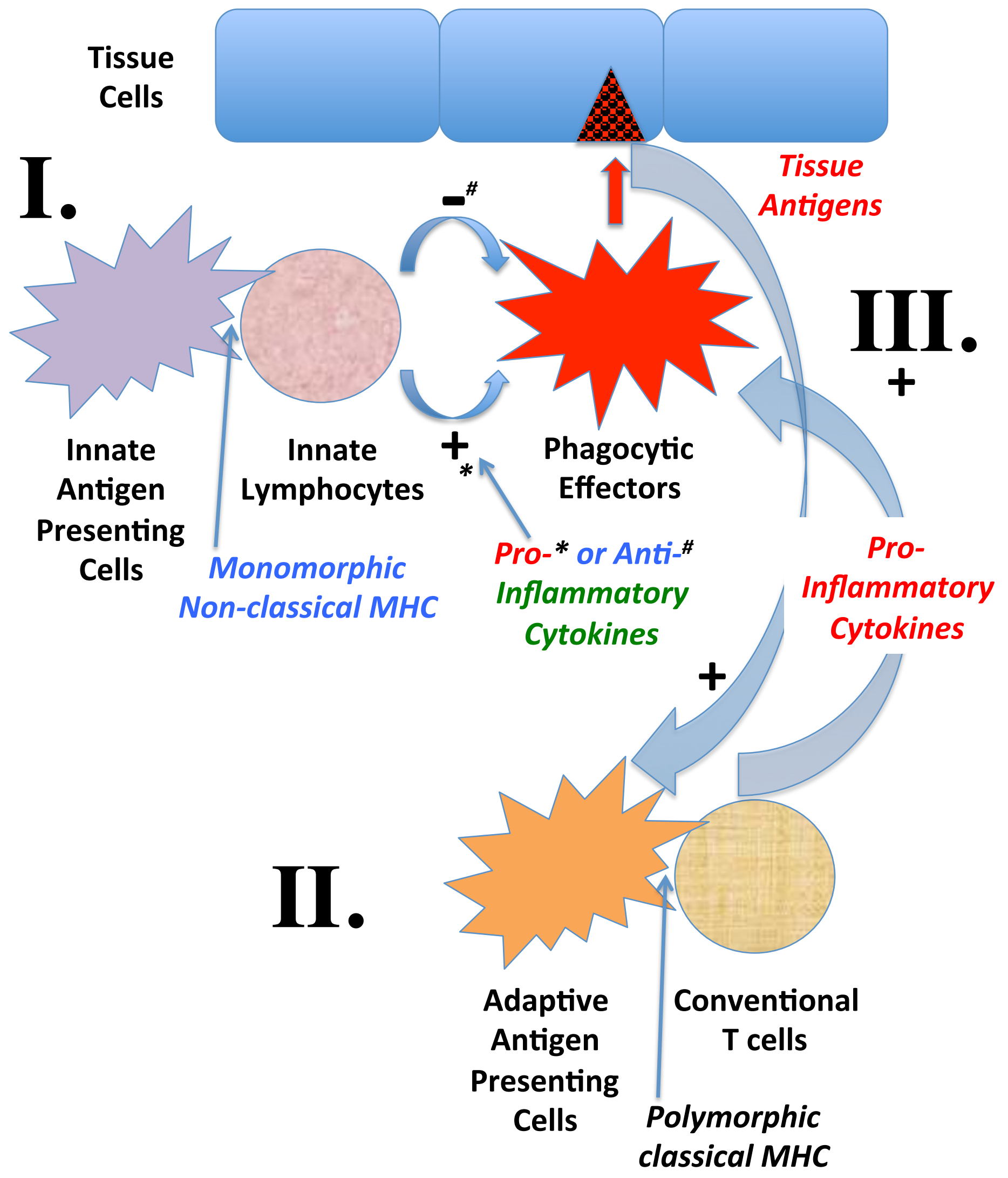


What's 'bad' in autoimmunity can be 'good' against cancer / infectious diseases

\section{\& vice versa}

Th1 / Th17 bias can be damaging in autoimmune diseases

Pro-inflammatory Th1 bias protective in cancer / infectious diseases, can fail in progressive cancer / infections

Recent cancer immunotherapies to 'unleash' Th1 responses often cause a specific subset of autoimmune phenomena such as vitiligo (melanoma), IBD, various endocrine damage

Increased lymphomas particularly in some autoimmune diseases:

chronic inflammation can be pro-

$$
\text { tumourigenic }
$$

